\title{
ENGAGING UNIVERSITY STUDENTS IN READING PROJECTS TO ENHANCE THEIR LEARNING
}

\author{
Brigitte Lenong \\ Mrs. Central University of Technology, Free State, South Africa, blenong@cut.ac.za
}

\begin{abstract}
In Higher Education students encounter large reading materials which require them to be independent readers. Therefore, this makes reading an important academic activity at higher education institutions. Students in this sector engage with different texts and books in their academic years, primarily to acquire information and knowledge. However, they appear not to read other materials to gain insight and for pleasure. Engaging students in reading activities is of importance, hence, reading projects are essential to enhance their reading habits. The research was conducted at University of Technology, to investigate the role of reading projects at tertiary level regarding students learning and reading ability. The study used a qualitative method design to explore the students' engagement in reading projects as to enhance their learning at the Central University of Technology, Free State. Focus group interviews were conducted with Reading Club members involved in reading projects. The findings of this study revealed that the reading projects made reading a shared pleasure, team effort and encouraged metacognitive focus upon learning. The study further provided insight into the role reading projects play in enhancing learning and promoting academic success.
\end{abstract}

Keywords: Reading, Reading projects, Engagement

\section{INTRODUCTION}

Previous studies done in South Africa reported that students at higher education institutions have poor reading ability and this affects their academic success (Pretorius 2002; Van Wyk 2001; Ngwenya 2010 \& Bharuthram 2012). Reading efficiency is the ability often seen as the essence of general reading comprehension that is formally understood as the interaction of strong reading rate abilities (Grabe \& Stroller 2002). Reading ability can be the strongest predictor of academic performance and readers need to acquire knowledge, improve language and acquire the necessary skills to do better academically (Pretorius 2002). In higher education institutions, reading is the most important academic activity, therefore students are required to be independent readers and have to cope with large amounts of reading materials (Bharuthram 2012). Many universities provide reading classes as part of their curriculum with a view of establishing the reading proficiency of first-year students. This is done through administering reading ability tests with a view to referring students with poor reading skills to reading classes or activities or projects which enhances students reading ability (Pretorius 2002).

In South Africa, the majority of students are taught through the medium of instruction which is not their primary language or home language which then leads to poor reading efficiency (Pretorius 2000; Pretorius,2002). Also, students' lack of motivation and interest to read has contributed to poor reading ability. As a measure to counteract the poor reading ability of higher education students at University of Technology, a reading club was established as an intervention to assist students improve their reading abilities. The aim of the reading club which engaged students in different reading projects, help them develop the love for reading, provide students with opportunities to explore different texts or books and have 
confidence in reading and develop a reading habit. Thus, different texts, books or literature can be explored effectively by students if only they are trained to discern or appreciate them, which is basically engaging students in reading. There is generally a lack of research based on the investigation of the role of reading projects in enhancing learning and promoting academic success in higher education institutions. The aim of this paper has therefore been to explore the role of reading projects at the University of Technology and how these interventions enhance students learning and reading ability.

The motivation of the study arose out of the researcher being involved in first-year reading development courses and realizing that first -year students were struggling to cope with reading material at a University of Technology, thus poor reading skills, poor reading ability and poor reading efficiency.

Central to understanding the students' engagement in reading projects to enhance their learning the paper commenced with an overview of perspectives on theoretical foundation and literature review of the reading process and followed by research design, methodology section and data analysis. Finally, the conclusion gives a brief summary and critique of the findings.

\section{THEORETICAL UNDERPINNINGS}

The Motivational framework provides theoretical point of departure for explaining the role of reading projects at university level and how they affect students' learning and reading ability. Wlodkowski (2003) points out that engagement in learning activities is a clear outcome of motivation, which directs energy to the goal. Whittingham and Huffman (2009) conducted a study on whether book clubs create student motivation to read. The results of the book club demonstrated that peer engagement had a positive correlation to the students' attitudes in reading. The results also indicated that the student population desired to read more often, but, had limited amount of reading resource available. In their study, Whittingham and Huffman (2009) concluded that a classroom environment which contains a vast array of literature selections increased students' intrinsic motivation to read. Therefore, engagement is crucial to motivation (Wittingham \& Huffman, 2009). Engaged readers become knowledgeable, strategic, creative and also improve on interpersonal relationships when they share or discuss books with their peers (Guthrie,2001). Very little if any learning can occur unless students are motivated on a consistent basis and this can be done by involving students in reading projects and providing a rich print environment to enhance learning (Guthrie, Hoa, Wigfield, Tonks \& Perencevich, 2006; Guthrie, Wigfield \& Humenick 2006). Bharuthram (2012) highlighted the literacy situation in South Africa and pointed out that serious attention should be given to teaching students reading strategies across curriculum and such strategies should be enforced through practice. Wittingham and Huffman (2009) studied the effects of book clubs on reading attitude of middle school students and pointed that exposure to book clubs has a positive effect on students. Furthermore, Niven (2005) points out that "reading is meaningdriven and is aided by students' exposure to a variety of texts in a print-rich environment". These studies shows that if students are exposed to different reading materials they will be motivated to learn and led to improved comprehension ability and intrinsic motivation.

Hence this study is informed by motivational conditions as mentioned by Wlodkowski $(2004,2008)$ which are important in motivating students in learning: namely;

Establishing inclusion: Creating a learning atmosphere in which reading club members feel respected by and connected to one another and developing a community of student readers. Students involved in reading groups were from different cultural groups and spoke different languages. Students took on the role of collaborative community members.

Developing attitude: Creating a favorable disposition toward the learning experience through personal relevance and choice. If students are involved in different reading activities by choice they will fully participate and enjoy. Students initiated and had control over the different reading projects.

Enhancing meaning: Creating challenging and thoughtful experiences to enhance learning. Reading projects should have a purposeful meaning to students whereby learning takes place. Students explored and participated in different reading activities to learn or gain knowledge.

Engendering competence: Creating an understanding that students will learn something they value. Exposure to reading materials and reading activities should have a positive effect on students.

In addition to the Motivation framework which is the theoretical basis of this study, the Vygotsky's Sociocultural learning theory also guided this study to explore the effectives of reading projects on learning. Sociocultural theories indicated that learning, thinking and knowing are derived from relations among people and arise from the daily and culturally structured world (Wang, 2007). Therefore, social interaction played a fundamental role in planning and structuring reading projects. Learning is embedded within social events, and social interaction plays a fundamental role in the improvement of learning (Wang, 2007). It was crucial 
that reading projects were well designed to help students gain knowledge, develop skills and improve their critical thinking. Students took part in activities that helped them express their personalities, interest, views and opinions.

Engaging students in different reading projects needed time, effort and resources to be invested in the reading projects, and thus enhances their learning outcomes, development and performance (Trowler, 2010).

The link between the Motivational framework and Sociocultural learning theory formed the basis on how reading projects were designed and contributed to the students learning.

\subsection{The construct of Reading Projects}

The reading club was established at the University of Technology to combat the poor reading ability of students. The aim of the reading club was to engage students in different reading projects, was to help students develop the love for reading, provide students with opportunities to explore different texts or books and have confidence in reading and develop a reading. The other aim of reading club is to encourage students to develop a love for reading and provided them with opportunities for in-depth exploration of books and stories at a relaxed environment. Book reviews were held fortnightly for 1 hour to 3hour sessions. Students had the freedom to read a book of their choice and interest. Once a quarter the club embarked on a community outreach project whereby they visited different schools or preschools or orphanage home to do activities like reading aloud, reading games, book reviews and spelling bee. The purpose of this project was to inculcate the culture of reading from grassroots level in designated communities, improve the reading skills of the learners, to build their reading confidence thereby ensuring that reading becomes a part of the learners lives and most importantly, to contribute to the community development.

The club held reading awareness campaigns at the university involving students in reading aloud sessions, reading games, spelling bee and reading speed competition.

The reading club collaborated with other institutions and the Reading Associations to start reading clubs in primary schools.

\section{AIM OF THE STUDY AND RESEARCH QUESTIONS}

The objective of the study was to investigate if engaging students in reading projects enhances their learning.

The study sought to answer the following research questions:

1. How did reading projects improve students' learning?

2. How did reading projects contribute to developing a community of students?

3. What kind of experience did students encounter when involved in different reading projects?

4. How can the reading club be improved?

\section{RESEARCH METHODOLOGY}

The current study applied interpretative approach for data collection. The primary focus was on capturing and describing the diverse way in which reading club members explore the students' engagement in reading projects to enhance their learning. The researcher used field notes which contained observations during the reading projects, the discussion held, as well as additional information provided by the participants to gain information about the effectiveness engaging students in reading projects to enhance their learning. The second part of the study was the focus group interviews. The focus group interviews were based on motivational conditions; establishing inclusion, developing attitude, enhancing meaning and engendering competence.

\subsection{Sample}

The population of this study comprised of 33 students, registered at the University of Technology and they were members of the reading club and participated in different reading projects. The sample method used in this research is purposeful sampling (Creswell, 2009; Maree \& Pietersen, 2010)

\subsection{Data Capturing and Processing}

The data capturing was conducted simultaneously with data collection, data interpretation and narrative report writing. The tape recordings and field notes were used to collect data which were transcribed 
verbatim. Categories and patterns which emerged from the data were then interpreted to provide explanations based on the motivational framework (Mcmillan \& Schumacher 2014).

\subsection{Ethical Considerations}

The researcher fully disclosed the purpose of the research to the participants and abided by the following ethical guidelines; namely; informed consent; privacy and confidentiality; seeking institutional permission and voluntary participation.

\section{DATA ANALYSIS AND DISCUSSION}

\section{Sample Profile of the participants}

The profile of this study's participants consisted of mainly 19-33 years old, female and male students who grew up in a less privileged residential area. The students were involved in diverse fields of academic qualifications at University of Technology that is Engineering, Health, Education and Management. Majority of the students $(60 \%)$ were doing their second year modules, $30 \%$ of the students were first year students and $10 \%$ third year students. The data sources consisted of field recordings, discussions during reading projects and focus group interviews. The data pertaining to the understanding of engaging students in reading projects to enhance their learning is presented below.

The observation form tracked reading material selected and the purpose of reading different reading materials.

Table 1 Reading Material

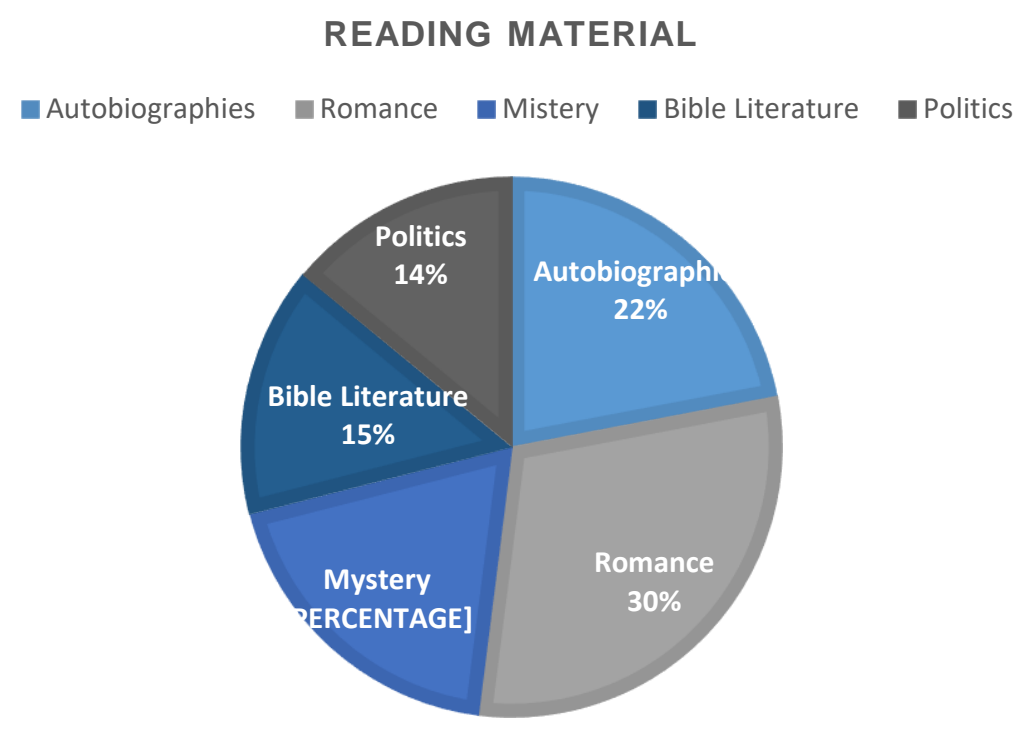

Table 1 indicates that participants read a variety of books with more students enjoying romance books. Students voiced diverse opinions with regard to the kind of books or reading. For example, some enjoyed autobiographies (22\%); others mystery (19\%), while $15 \%$ reveled in Bible literature. However, only $5 \%$ of the participants were exposed to reading computer articles or electronic educational programs.

Table 2: CUT Students' reading frequency per week

\begin{tabular}{|c|c|}
\hline How often was reading done & Frequency $\%$ \\
\hline $1-2$ times a week & $11 \%$ \\
\hline $3-5$ times a week & $55 \%$ \\
\hline More than 5 times a week & $34 \%$ \\
\hline
\end{tabular}

According to Table 2, most of the CUT students (55\%) read three to five times a per week, $34 \%$ of the respondents declared that they read more than five times a week. Only $11 \%$ of these respondents indicated that they read once or twice a week. 
Table 3: Engagement in reading projects

\begin{tabular}{|l|l|}
\hline Reading Projects & Frequency \% \\
\hline Book reviews & $95 \%$ \\
\hline Reading aloud & $89 \%$ \\
\hline Community reading projects & $78 \%$ \\
\hline Reading competition & $83 \%$ \\
\hline Reading excursions & $79 \%$ \\
\hline Reading awareness Campaign & $86 \%$ \\
\hline
\end{tabular}

The field notes indicated that majority of the students participated actively in different reading projects and the bigger attendance was in the book review discussions, followed by reading aloud activities. On average participants were actively involved in reading projects.

Following the demographic information of the sample and reading habits, the results are presented according to the categories from the motivational condition as follows:

Enhancement of meaning/learning

Students were asked to indicate if the reading club projects has assisted them to improve their learning. A majority of the respondents $(96 \%)$ perceived that the course improved their learning and they were performing better in their academic activities since joining the reading club and being involved in different reading projects.

The points made by the respondents are categorized and presented below:

Realised the importance of reading for pleasure; contributed to academic work; improved understanding of analysing texts; learnt to work in a team with members of diverse cultures and personalities; gained knowledge about other fields; improved reading and writing skills; improved extensive reading skills; learnt to instil love of reading to young people in the community; focused on their studies and therefore results improved; built self-confidence; able to engage with other people; understood the context of their work; improved presentation skills.

Developing community of students (inclusion)

Students indicated several reasons of what motivated them to join the reading club and confirmed diverse reasons such as learn to read, enjoyment, improving their ability to memorize, gaining a lot of knowledge and improving literacy skills. The reasons highlighted by student participants are evidenced by the following remarks in the box below.

\section{- 'Changing the myth about black people do not read'}

- 'Sense of belonging'

- 'Keep myself busy'

- 'To write a book'

- 'Meet people with the same vision'

- 'Love for reading'

- 'To be a leader'

- 'Being part of the family that love what I love'

- 'To be a giver'

- 'To share knowledge'

- 'I felt important' 
The majority of students $(80 \%)$ of the participants indicated that they enjoyed student-led discussions as they were free to express their views and opinions, asked more questions and fully took part in discussions.

Students experiences in reading projects

The subsequent data examined the kind of experience did students encountered when involved in different reading projects. All respondents have indicated that reading projects helped to increase their learning and improved their knowledge. The comments made by the respondents are categorized and presented below.

- By sharing different genres, were able to learn from others

- Improved my vocabulary

- Importance of academic excellence

- Aspiration to inspire other

- To be a great leader

- Communication skill development

- How to plan projects, seek funding

- Patience and understanding

- Seeing things in a different perspective

- Passion and energy to read

- Helped me to open up easily

A testimony to the kind of experiences students encountered are highlighted by the following statements:

One of the projects I personally love is the community outreach project. The members of the club contribute in any way they can, last time we visited sun flower hospice. We spent time with the children, had fun activities were the kids could participate and did some word to help the stuff. This project made me realize that the simple things we do can sometimes make a huge difference in someone's life.

We also had some team building trips where we get to know each other much better, since I joined the club we went to golden gate two times and I was aided to overcome most of my fears with the help of some of the activities and I noticed that one needs to connect with nature to feel fresh and relaxed. We also went to other amazing places where I learnt a lot about myself.

\section{Areas that need improvement:}

Participants were asked to indicate how the reading club can be improved. They indicated that funding is needed for all the projects and felt that the contact sessions were not adequate. The other issue raised was that workshops need to be held for members as to equip them with knowledge and skills about reading.

\section{CONCLUSIONS}

The study shows that reading projects have a positive effect on student learning and creating meaning. The findings in the survey revealed that participants realized the value of being involved in reading projects and it contributed to inclusion, motivation, attitude and meaning. It is evident that increased reading improves reading proficiency and also enhances learning. The effects of reading projects have been successful in increasing students' knowledge and skills. The results of this study revealed that well-designed reading activities will engage and motivate students in learning and develop their critical thinking (Wang 2007). The meaning was found in involvement in different reading projects not the number of books read. Basically creating challenging and thoughtful experiences to enhance learning was based on the involvement in reading projects not on the number of books read. It is therefore recommended that implementation of reading projects at institutions of higher learning can improve students' learning and lead to academic success. The findings revealed that the reading projects made reading a shared pleasure, team effort and encouraged metacognitive focus upon learning. The study provided insight into the role reading projects play in enhancing learning and promoting academic success amongst university students. 


\section{REFERENCE LIST}

Bharuthram, S. 2012. Making a case for the teaching of reading across the curriculum in higher education. South African Journal of Education 32:205-214.

Creswell, J.W. (2009). Research Design: Qualitative, Quantitative, and Mixed Methods Approaches. Sage Publications.

Grabe, W. and Stoller, F (2002). Teaching and researching reading. Harlow, UK: Longman.

Guthrie, J.T. (2001). Contexts for engagement and motivation in reading. Reading Online, 4 (S). Available: http://www.readingonline.org/articles/art index.asp?HREF=/articles/handbook/guthrie/index.html

Pretorius, E.J. 2002. Reading ability and academic performance in South Africa: Are we fiddling while Rome is burning? Language Matters, 33:169-196.

Pretorius, E.J. 2000. What they can't read will hurt them: Reading and academic achievement. Innovation 21:33-41.

Pretorius, E.J. 2002a. Reading ability and academic performance in South Africa: Are we fiddling while Rome is burning? Language Matters: Studies in the Languages of Southern Africa 33:169-196.

Pretorius, E.J. 2002b. Reading and Applied Linguistics - a deafening silence. South African Linguistic \& Applied studies 20:91-103.

Guthrie, J., Hoa, L., Wigfield, A., Tonks, S., \& Perencevich, K. (2006). From sparks to fire: Can situational reading interest lead to long-term reading motivation? Reading Research and Instruction, 45 (2), 91 117.

Guthrie, J., Wigfield, A., \& Humenick, N. (2006). Influences of stimulating tasks on reading motivation and comprehension. The Journal of Educational Research, 99 (4), 232- 245.

Maree, K., \& Pietersen, J. (2010). Sampling. In First steps in Research (ed), by Maree, K. p172-181. Van Schaik, Pretoria.

McMillan, J.H.\& Schumacher, S., 2014. Research in education: Evidence-based inquiry. Pearson Higher Ed.

Niven, P.M. 2005. Exploring first year students' and their lectures' constructions of what it means to read in a humanities discipline: A conflict of frames? South African Journal of Higher Education 19(4):777789.

Ngwenya T 2010. Correlating first-year law students' profile with the language demands of their content subjects. Per Linguam 26, 74-99.

Trowler, V., 2010. Student engagement literature review. The higher education academy, 11, pp.1-15.

Wang, L. 2007. Sociocultural learning theories and information literacy teaching activities in higher education. Reference \& User Services Quarterly, 47(2): 149-158.

Whittingham, J. \& Huffman, S. (2009). The effects of book clubs on the reading attitudes of middle school students. Reading Improvement, 46(3), 130-136.

Wlodkowski, Raymond J., (2004) Creating Motivating Learning Environments, In Galbraith, Michael W., Adult Learning Methods: A Guide for Effective Instruction (3rd ed.), Malabar, FL: Krieger Publishing Company.

Wlodkowski, R. J. 2008. Enhancing adult motivation to learn: A comprehensive guide for teaching all adults. 3rd ed. San Francisco: Jossey-Bass. 